\title{
HEARING STATUS IN HIGH RISK NEONATES: A CROSS-SECTIONAL STUDY
}

\author{
SAHA ${ }^{1}$, SAHA NC ${ }^{2}$, SAHA KL ${ }^{3}$, TALUKDER DC ${ }^{4}$, DATTA PG ${ }^{5}$
}

\begin{abstract}
Objective: To assess hearing status and to identify the risk factors for hearing impairment among high risk neonates, a descriptive type of cross-sectional study was done over a period 6 months, from January to July 2009, in the Special Care Baby Unit of Dhaka Medical College Hospital (DMCH), Bangabandhu Sheikh Mujib Medical University (BSMMU) Hospital \& BIRDEM Hospital, Dhaka.

Methods: Sixty high risk neonates (20 from each center) having one or more risk factors for hearing impairment were screened. "Four-level" protocol was applied for assessment of hearing status using Transient Evoked Oto-acoustic Emission (TEOAE), Automated Auditory Brainstem Response (Screening $A A B R$ ) as screening tests and diagnostic Auditory Brainstem Response (Diagnostic $A B R$ ) test for confirming hearing impairment. First screening was done by TEOAE before discharge from hospital. Second screening was done at 3 months of age by TEOAE and Screening AABR. Diagnostic ABR to confirm hearing loss was applied at 6 months of age. The collected data was statistically analyzed. Here proportion of hearing impairment among high risk neonates and relationship of risk factors with hearing status.

Results: Among high risk neonates 38.33\% had very low birth weight, 21.67\% had septicemia, $16.67 \%$ had birth asphyxia as well as hyperbilirubinemia requiring exchange transfusion, $1.67 \%$ had TORCH infection and 5\% required mechanical ventilation. Birth asphyxia was found as significant risk factor. The percentage of permanent hearing impairment was $1.66 \%$ that is 16.6 per 1000 neonates.

Conclusion: Very low birth weight was found as the commonest risk factor and birth asphyxia was a significant risk factor for hearing impairment at initial screening. As this study was conducted on small number of high risk neonates universal newborn hearing screening at a tertiary level hospital may find out the real incidence of hearing impaired neonates and infant.

Key words: Risk factors, hearing impairment, high risk neonates.
\end{abstract}

J Dhaka Med Coll. 2012; 21(2) : 166-176.

\section{Introduction:}

High risk neonates are those who have a greater chance of complications because of some predisposing condition that occur during fetal development or during labor and birth. The complications of these high risk neonates include developmental delay, ${ }^{1}$ cerebral palsy and mental retardation ${ }^{2}$ and isolated motor, hearing, speech, language and behavioral problem. ${ }^{3}$
Among them one of the preventable disability is sensorineural hearing impairment. ${ }^{4}$

According to the statement of Joint Committee on Infant Hearing (JCIH) ${ }^{5} 1994$, risk factors for hearing impairment among newborn are: Family history of permanent childhood sensorineural hearing loss, intrauterine infection (TORCH), craniofacial

1. Dr Anamika Saha, Department of Paediatrics, Bangabandhu Sheikh Mujib Medical University (BSMMU), Dhaka.

2. Dr. Narayan Chandra Saha, Associate Professor, Department of Paediatrics, Dhaka Medical College, Dhaka.

3. Dr. Kanu Lal Saha, Assistant Professor, Department of Otolaryngology, Head \& Neck Surgery, Bangabandhu Sheikh Mujib Medical University (BSMMU), Dhaka.

4. Dr. Debesh Chandra Talukder, Assistant Professor, Department of Otolaryngology, Head \& Neck Surgery, Dhaka Medical College, Dhaka

5. Prof. Pran Gopal Datta, Professor of Otolaryngology, Head \& Neck Surgery, and Vice-Chancellor, Bangabandhu Sheikh Mujib Medical University (BSMMU), Dhaka.

Correspondence : Dr Anamika Saha, Department of Paediatrics, Bangabandhu Sheikh Mujib Medical University (BSMMU), Dhaka. E-mail: drklsaha@gmail.com 
anomalies, hyperbillirubinemia at a serum level requiring exchange transfusion, birth weight $<1500 \mathrm{gm}$, use of ototoxic medication (e.g. amino-glycosides, diuretics etc.) in potentially toxic doses, bacterial meningitis, severe birth asphyxia APGAR $<4$ at $1 \mathrm{~min}$. or $<6$ at 5 min., mechanical ventilation $>4$ days, syndromes associated with sensorineural hearing loss.

The prevalence of moderate to severe bilateral sensorineural hearing loss is 4-5 per 1000 high-risk newborn ${ }^{6}$. The incidence of hearing impairment varied in different studies such as 3.14 per 1000 in Texas, USA, ${ }^{7} 5.2$ per 1000 in Taiwan, ${ }^{8} 5.3$ per 1000 in Nigeria, ${ }^{9} 5.6$ per 1000 in India ${ }^{10}$ and Hong Kong, ${ }^{11} 7.9$ per 1000 in Pakistan, ${ }^{12} 11.4$ per 1000 in Jordan ${ }^{13}$ and 12.0 per 1000 in Oman. ${ }^{14}$

In 1999, American Academy of Pediatrics Task Force on Newborn and Infant Hearing stated that significant bilateral hearing loss has been shown to be present in approximately 1 to 3 per 1000 newborns in the well-baby nursery population, and in approximately 2 to 4 per 1000 infants in the intensive care unit population. ${ }^{15}$ A retrospective study conducted by Connolly et al at Mississippi State, USA in 2005 found that 1 of every 811 infants without risk factors and 1 of every 75 infants with risk factors have hearing loss. ${ }^{16}$

Early detection of hearing deficit and appropriate intervention are essential to assist speech, language and cognitive development. ${ }^{17}$ Currently the predominant mode of detection remains parental suspicion of hearing impairment usually observed after 2 year of age, ${ }^{18}$ when potentiality of development of immature brain is already over. Therefore late detection of hearing impairment may impede opportunities for optimal intervention for speech and language development. ${ }^{9}$

Neonatal hearing screening must be performed for early detection of hearing impairment among high-risk group. Thus the resultant situation raises high concern, since no curative treatment is available for hearing loss except cochlear implant which is a very costly, complex procedure and requires skilled personnel. Thus it may not be economically feasible for lower socioeconomic community. It is therefore essential to identify state of hearing impairment as early as possible to provide early rehabilitative therapy like hearing aids, speech therapy etc. so as to utilize full advantage of plasticity of developing sensory system among children in their very early growing period of brain.

Studies have shown that early intervention is more effective in terms of better speech intelligibility that could be predicted with hearing aids fitted before 6 month of age. ${ }^{19}$ Therefore early identification of hearing deficit is mandatory.

There are many ways to detect hearing impairment in children. In developing countries like ours, we need a protocol, which is less time consuming, user friendly but at the same time accurate in detecting hearing impairment. ${ }^{20}$ Transient Evoked Otoacoustic Emission (TEOAE) is reproducible, diagnostically accurate, easy to perform and minimally invasive. Currently it is the method of choice particularly for neonatal audiological screening among high-risk infants ${ }^{21}$ and general population. ${ }^{22}$

TEOAE also represents a quick, inexpensive, frequency specific, valid method for testing cochlear function ${ }^{23}$. But it can be misleading in case of wax packed ear canal, middle ear effusion and influence of external noise as these conditions often confound the real audiological output. Moreover TEOAE cannot identify auditory neuropathy.

Automated ABR (AABR) is used for assessing auditory function; therefore it detects function of eight nerves through the auditory brainstem. So it can detect cochlear hearing loss as well as neural hearing loss (Auditory neuropathy). AABR method produces tracings that simply represents pass or refer result without requiring any interpretation and the test can be conducted in the presence of background noise. But it cannot be used to determine the degree or nature of hearing loss. ${ }^{24}$ 
Auditory Brainstem Response (ABR) audiometry however, is not influenced by conditions which affects TEOAE response. So it is better than TEOAE and can also identify auditory neuropathy. ABR is costly, time-consuming and requires trained personnel. Since it requires electrode preparation, placement and removal, ${ }^{25}$ therefore it is not recommended to be the first choice for screening of hearingimpaired child and thus is used to confirm hearing loss.

It is a general consensus now that all the infants should be screened preferably before postnatal discharge. But one study showed that the specificity of TEOAE is lowest at this time and increases significantly at 3 months of age. ${ }^{20}$

High-risk neonates develop transient hearing loss in considerable number of cases but in some cases hearing loss persists. A study showed that incidence of significant hearing impairment in high-risk neonate was $18 \%$ which was persistent in $4 \%$ of cases on follow up at 6 month of age using ABR. ${ }^{26}$ The aim of the study was to assess hearing status of high risk neonates, to identify relationship of underlying risk factors for hearing impairment in studied neonates and to assess the proportion of permanent hearing loss among high risk newborn.

\section{Methods}

This study was conducted in the Special Care Baby Unit of Dhaka Medical College Hospital (DMCH), Bangabandhu Sheikh Mujib Medical University (BSMMU) Hospital, and Bangladesh Institute of Research \& Rehabilitation in Diabetes, Endocrine and Metabolic Disorders (BIRDEM) Hospital, Dhaka, from January to July 2009. It was a descriptive type of crosssectional follow-up study. The study subjects were 60 (sixty) high risk neonates (20 cases from each center) having one or more risk factors for hearing impairment like maternal diabetes mellitus, hypertension, ante-partum haemorrhage, premature rupture of membrane and factors related to newborn like low-birth weight, asphyxia, sepsis, meningitis, TORCH infection, hyperbilirubinaemia, ventillatory support and use of ototoxic drugs. Enrollment of cases were done twice in a week from each center so as to maintain homogeneity because based on service delivery system, the above centers entertain patients from different geographical and socio-economic status of Bangladesh. Two consecutive cases were selected on each day as per inclusion criteria. Healthy, term babies with birth weight $>2.5$ $\mathrm{kg}$ and normal perinatal period (1 min APGAR $>8$ ) were excluded from the study. Data was collected through a pre-tested structured questionnaire that included information pertaining to hearing impairment that could arise from the parents and the newborn. First hearing screening was done by Transient Evoked Otoacoustic Emission (TEOAE) before discharge from hospital. If result was "pass" which indicate normal hearing, patient was discharged and no further follow up was done. If result was "Refer" which indicate abnormal hearing, second hearing by repeat TEOAE was done at 3 months of age. If result was passed no further follow up was done. If result is referred automated Auditory Brainstem Response (AABR) was done simultaneously at 3 months of age. If AABR result was passed, no further follow-up was recommended. If result was referred patient was followed up and diagnostic ABR was done at 6 months of age. If any patient did not come for follow-up at schedule time he/she was excluded from the study. All the audiological evaluation was done in the Department of Otolaryngology, BSMMU, by trained personnel. Periodic recheck was also done to maintain consistency of results. Ethical clearance was obtained from ethical review committee of BSMMU. Statistical analysis was done by using SPSS version 17.0. All qualitative data were presented by frequency and percentage and chi-square test was used, for statistical significance. $\mathrm{P}$ value $<0.05$ was considered as statistically significant. 


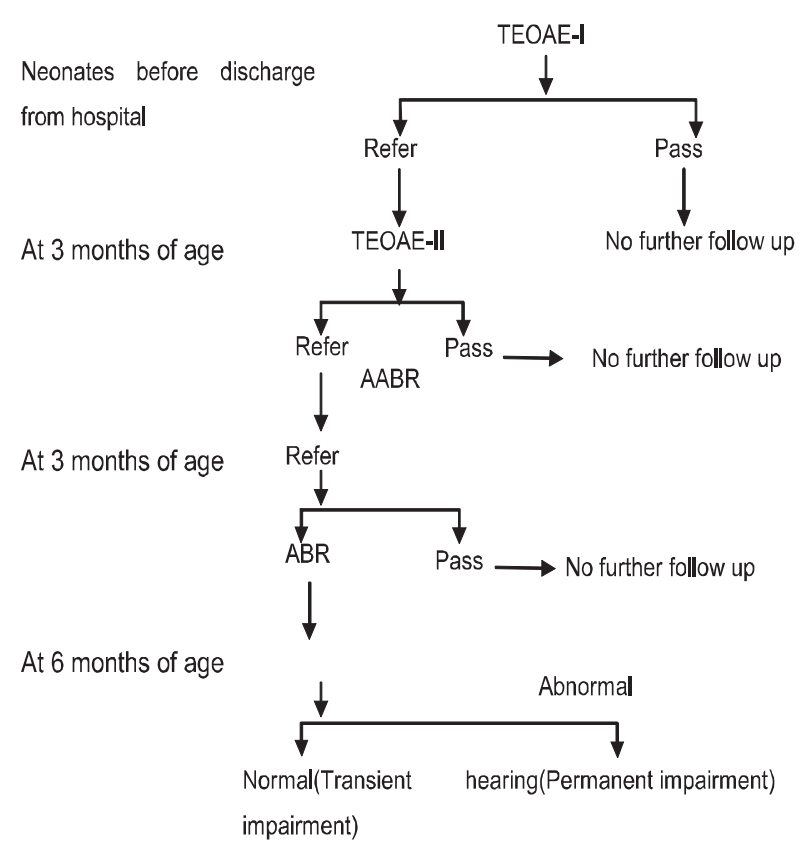

Fig.-1: Hearing Screening Protocol

\section{Results:}

In this study, female neonates were twice $(n=40)$ in number than that of male $(n=20)$ (Table-I). One third had normal delivery (TableII). About one fourth of neonates had no maternal risk factors (Table -III) .Distribution of patients by high risk criteria showed low birth weight was the commonest risk factor (38.3\%) (Table-IV).

Table- I

Distribution of the patients by $\operatorname{sex}(n=60)$

\begin{tabular}{lcc}
\hline Sex & Frequency & Percent \\
\hline Male & 20 & 33.3 \\
Female & 40 & 66.7 \\
\hline Total & 60 & 100.0 \\
\hline
\end{tabular}

Table- II

Distribution of the patients by mode of delivery $(n=60)$

\begin{tabular}{lcc}
\hline Mode of delivery & Frequency & Percent \\
\hline Vaginal & 20 & 33.3 \\
LUCS & 40 & 66.7 \\
\hline Total & 60 & 100.0 \\
\hline
\end{tabular}

Table-III

Distribution of the patients by maternal risk factor $(n=60)$

\begin{tabular}{lcc}
\hline Risk factor & Frequency & Percent \\
\hline PROM & 5 & 8.3 \\
HTN & 18 & 30.0 \\
APH & 6 & 10.0 \\
DM & 15 & 25.0 \\
No risk factor & 16 & 26.7 \\
\hline Total & 60 & 100 \\
\hline
\end{tabular}

LUCS - Lower uterine caesarian section, HTNHypertension, DM-Diabetes mellitus, APH - Anti partum hemorrhage, PROM - Premature rupture of membrane

\section{Table-IV}

Distribution of patients according to neonatal risk factors for hearing impairment.

\begin{tabular}{|c|c|c|}
\hline Variable & Frequency & Percent \\
\hline \multicolumn{3}{|c|}{ Gestational age } \\
\hline Preterm & 36 & 60.0 \\
\hline Term & 24 & 40.0 \\
\hline \multicolumn{3}{|c|}{ Birth weight <1500gm } \\
\hline Yes & 23 & 38.3 \\
\hline No & 37 & 61.7 \\
\hline \multicolumn{3}{|l|}{ Asphyxia } \\
\hline Yes & 10 & 16.7 \\
\hline No & 50 & 83.3 \\
\hline \multicolumn{3}{|l|}{ Sepsis } \\
\hline Yes & 13 & 21.6 \\
\hline No & 47 & 78.4 \\
\hline \multicolumn{3}{|c|}{ Meningitis } \\
\hline Yes & 3 & 5.0 \\
\hline No & 57 & 95.0 \\
\hline \multicolumn{3}{|c|}{ Exchange transfusion } \\
\hline Yes & 10 & 16.7 \\
\hline No & 50 & 83.3 \\
\hline \multicolumn{3}{|c|}{ Mechanical ventilation $>4$ days } \\
\hline Yes & 3 & 5.0 \\
\hline No & 57 & 95.0 \\
\hline \multicolumn{3}{|l|}{ TORCH } \\
\hline Yes & 1 & 1.7 \\
\hline No & 59 & 98.3 \\
\hline \multicolumn{3}{|c|}{ Ototoxic drug $>5$ days } \\
\hline Yes & 10 & 16.6 \\
\hline No & 50 & 83.3 \\
\hline
\end{tabular}


At $1^{\text {st }}$ hearing screening $33.33 \%(n=20)$ was referred by TEOAE (Table-V). The proportion of patients referred at $2^{\text {nd }}$ screening by TEOAE and AABR method was 35\% $(n=7)$ and $42.86 \%$ $(\mathrm{n}=3)$ respectively (Table-VI \& VII). At this stage of hearing assessment, out of 60 cases, only 3 cases $(5 \%)$ were referred, indicating abnormal hearing (Fig-VI).

The third hearing assessment to confirm hearing loss at 6 month of age was done through diagnostic ABR, which showed abnormal ABR in one case out of 3 cases referred at $2^{\text {nd }}$ screening. Finally only one case $(1.67 \%)$ had hearing loss, out of 60 enrolled cases (Table-VIII \& Fig-VI).

Maternal risk factors like hypertension, diabetes mellitus, antepertum hemorrhage and premature rupture of membrane had no statistical significance $(p>0.5)$ regarding pass and refer result by TEOAE (Table-IX). The hearing status of high risk neonates evaluated by TEOAE during $1^{\text {st }}$ screening showed that neonatal risk factor like birth asphyxia was significantly associated with abnormal hearing("Refer") (p=0.02) (Table-X). No association was observed between hearing status by TEOAE at $3^{\text {rd }}$ month and neonatal risk factors (Table-XI).
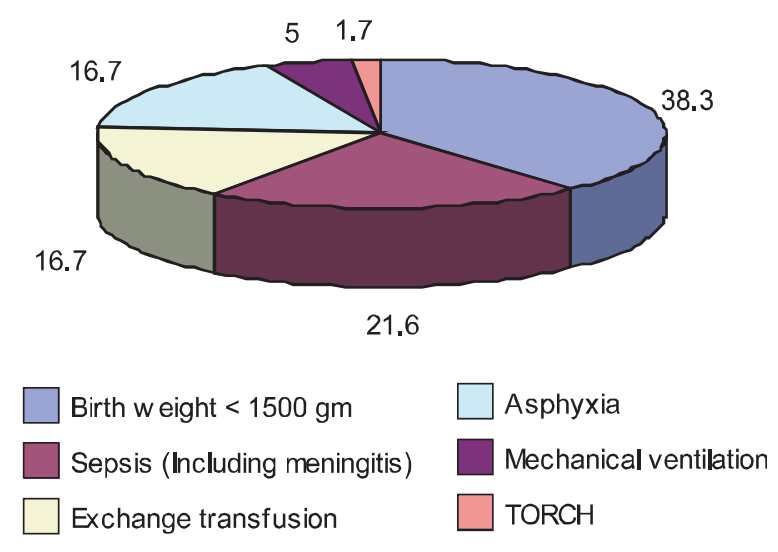

Fig.-2: Distribution of patients by high risk criteria
The high risk group including birth weight $<1500$ gm were the commonest finding (38.3\%) followed by sepsis $(21.7 \%)$ including meningitis (5\%), exchange transfusion (16.7\%) and birth asphyxia $(16.7 \%)$ respectively while mechanical ventilation (5.03\%) and TORCH infection $(1.7 \%)$ were the less common.

\section{Table- V}

Distribution of patients by $1^{\text {st }}$ Hearing Screening by TEOAE before discharge from hospital $(n=60)$

\begin{tabular}{lcc}
\hline TEOAE & Frequency & Percent \\
\hline Pass & 40 & 66.67 \\
Refer & 20 & 33.33 \\
\hline Total & 60 & 100 \\
\hline
\end{tabular}

First neonatal hearing screening was done by TEOAE before discharge from the hospital. Out of 50 screened neonates by TEOAE 40 cases $(66.67 \%)$ were passed and 20 cases $(33.33 \%)$ were referred.

Table- VI

Second Hearing Screening by TEOAE at 3 month of age $(n=20)$

\begin{tabular}{lcc}
\hline TEOAE & Frequency & Percent \\
\hline Pass & 13 & 65 \\
Refer & 7 & 35 \\
\hline Total & 20 & 100 \\
\hline
\end{tabular}

Second time hearing screening was done by TEOAE at 3 months of age. Out of 20 retested cases 13 cases (65\%) were passed and 7 cases $(35 \%)$ were referred.

Table- VII

Second Hearing Screening by AABR at 3 months of age $(n=7)$

\begin{tabular}{lcc}
\hline AABR & Frequency & Percent \\
\hline Pass & 4 & 57.14 \\
Refer & 3 & 42.86 \\
\hline Total & 7 & 100.00 \\
\hline
\end{tabular}


During second time hearing screening refer cases detected by TEOAE were tested by AABR at 3 months of age. Seven cases were tested by AABR of which 4 cases $(57.14 \%)$ were passed and 3 cases $(42.86 \%)$ were referred.

\section{Table- VIII}

Third Hearing Screening by ABR at 6 months of age $(n=3)$

\begin{tabular}{lcc}
\hline ABR & Frequency & Percent \\
\hline Normal & 2 & 66.67 \\
Abnormal & 1 & 33.33 \\
\hline Total & 3 & 100.00 \\
\hline
\end{tabular}

Abnormal finding recorded by AABR at 3 months of age was reassessed by ABR at 6 months of age. Out of initial 3 referred cases 2 cases $(66.67 \%)$ were found normal and 1 case (33.33\%) was found abnormal.

Table- IX

Distribution of the patients by Hearing status and maternal risk factor.

\begin{tabular}{lccc}
\hline Variables & $\begin{array}{c}\text { Hearing Status } \\
\text { Pass }\end{array}$ & $\begin{array}{c}\text { P value } \\
\text { Refer }\end{array}$ & $\begin{array}{c}\text { Chi square } \\
\text { test }\end{array}$ \\
\hline HTN & $12(66.7)$ & $6(33.3)$ & 1.00 \\
APH & $3(50.0)$ & $3(50.0)$ & 0.361 \\
DM & $9(60.0)$ & $6(40.0)$ & 0.361 \\
PROM & $4(80.0)$ & $1(20.0)$ & 1.00 \\
\hline
\end{tabular}

Figure within parenthesis denoted corresponding row percentage.

There was no statistical significance between pass \& refer group regarding maternal risk factors.

The hearing status of risk factors evaluated by TEOAE in neonates during $1^{\text {st }}$ screening was listed in the above table. Among these risk factors birth asphyxia was statistically significant $(p=0.02)$.

\section{Table-X}

Distribution of the patients by hearing status and high risk factor after $1^{\text {st }}$ screening by TEOAE

\begin{tabular}{|c|c|c|c|}
\hline \multirow[t]{2}{*}{ Preterm } & \multicolumn{2}{|c|}{ Hearing Status } & \multirow{2}{*}{$\begin{array}{l}\mathrm{P} \text { value } \\
\text { (x2 test) }\end{array}$} \\
\hline & Pass & Refer & \\
\hline$\overline{\text { Yes }}$ & $24 \overline{(66.7)}$ & $12(33.3)$ & 1.00 \\
\hline \multicolumn{4}{|c|}{ Birth weight < 1500gm } \\
\hline Yes & $17(73.9)$ & $6(26.0)$ & 0.707 \\
\hline \multicolumn{4}{|c|}{ Asphyxia } \\
\hline Yes & $3(30.0)$ & $7(70.0)$ & 0.02 \\
\hline \multicolumn{4}{|l|}{ Sepsis } \\
\hline Yes & $10(76.9)$ & $3(23.0)$ & 0.223 \\
\hline \multicolumn{4}{|c|}{ Meningitis } \\
\hline Yes & $2(66.7)$ & $1(33.3)$ & 1.00 \\
\hline \multicolumn{4}{|c|}{ Exchange transfusion } \\
\hline Yes & $8(80.0)$ & $2(20.0)$ & \\
\hline No & $33(66.0)$ & $17(34.0)$ & 1.00 \\
\hline \multicolumn{4}{|c|}{ Mechanical ventilation $>4 d$} \\
\hline Yes & $2(66.6)$ & $1(33.3)$ & .53 \\
\hline \multicolumn{4}{|l|}{ TORCH } \\
\hline Yes & $0(.0)$ & $1(100.0)$ & 1.00 \\
\hline \multicolumn{4}{|c|}{ Ototoxic drug $>5$ days } \\
\hline Yes & $20(66.67)$ & $10(33.33)$ & 0.60 \\
\hline \multicolumn{4}{|c|}{ NICU care $>5$ days } \\
\hline Yes & $35(87.5 \%)$ & $18(30.0)$ & \\
\hline
\end{tabular}

Figure within parenthesis denoted corresponding percentage.

Chi square test was done to measure the level of significance. Here, $\mathrm{p}<0.05$ was considered as level of significance.

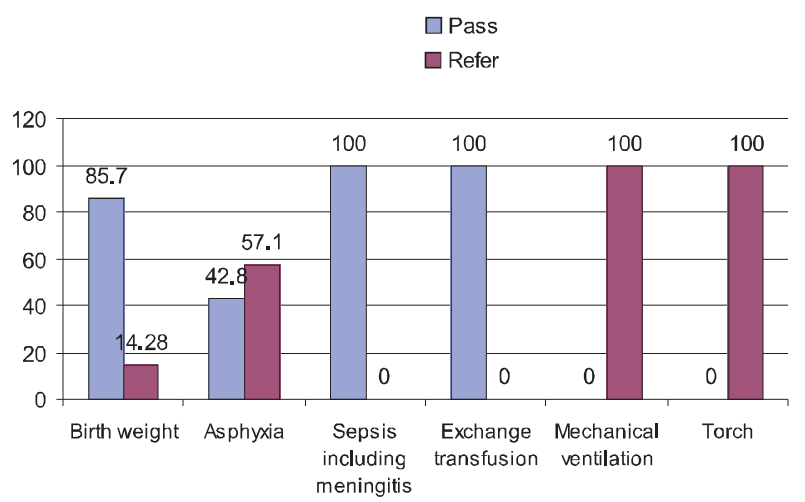

Fig-3: Hearing status among high risk group after $1^{\text {st }}$ screening by TEOAE

Figure showed distribution of high risk neonates according to hearing status. In case of birth weight $<1500 \mathrm{gm} 73.9 \%$ were passed and $26.0 \%$ were referred. In sepsis $76.9 \%$ were 
passed and 23\% were referred.70\% was referred and 30\% were passed in asphyxiated patient. In hyperbilirubinemia requiring exchange transfusion, $80 \%$ were passed and $20 \%$ were referred. In mechanical ventilation $66.6 \%$ were passed and $33.3 \%$ were referred. It was also found that $100 \%$ patient with TORCH positive were referred.

\section{Table-XI}

Distribution of patient by hearing status and high risk factors after 2nd screening by TEOAE

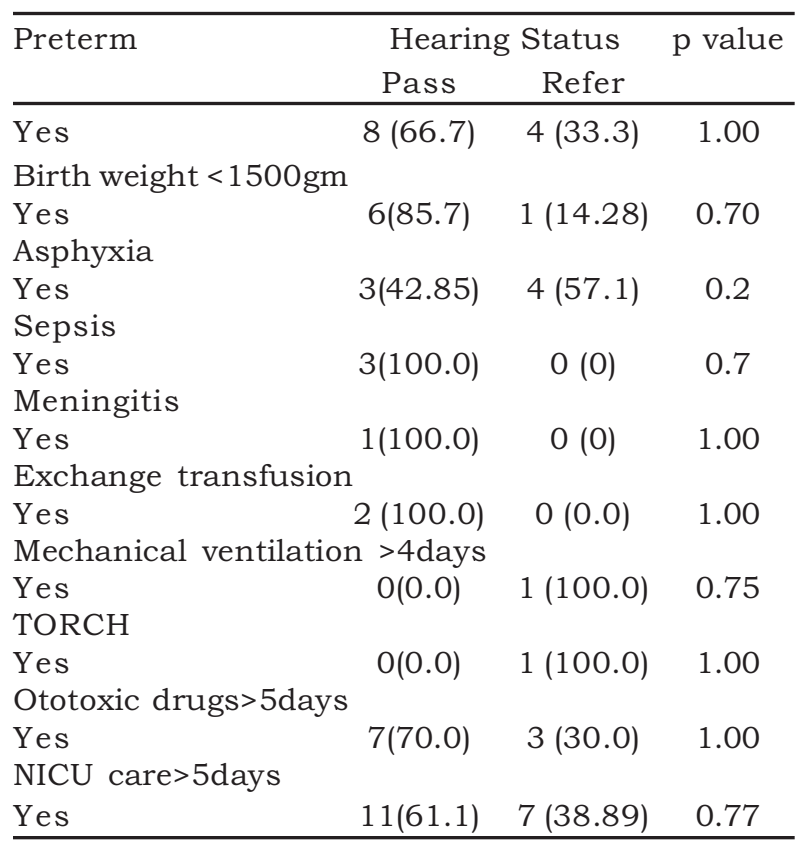

Figure within parenthesis denoted corresponding percentage

Chi square test was done to measure the level of significance. A p value <.05 was considered as level of significance

\section{$\square$ Pass $\square$ Refer}

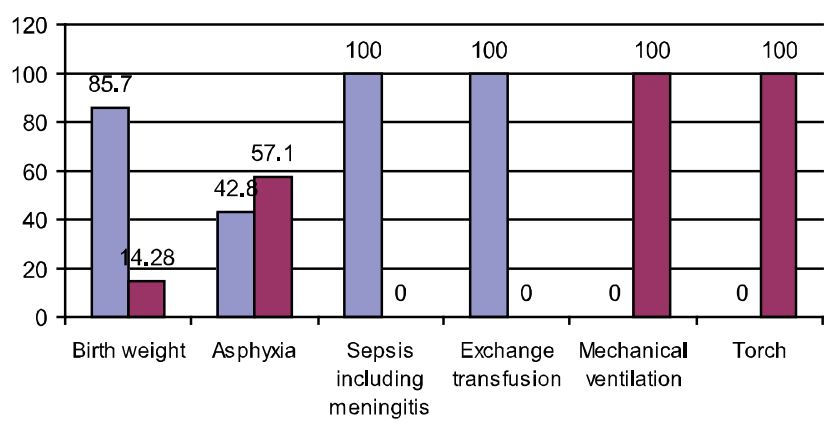

Fig.-4: Hearing status among high risk group after $2^{\text {nd }}$ screening by TEOAE
The hearing status of risk factors evaluated by TEOAE in neonates during $2^{\text {nd }}$ screening are listed in the above table along with calculated chi-square and $\mathrm{P}$ values. Among these risk factors none was found statistically significant.

Figure showed distribution of high risk neonates according to hearing status. In patient with birth weight $<1500$ gm $85.7 \%$ were passed and $14.28 \%$ were referred. In case of asphyxia $42.8 \%$ were passed and $57.1 \%$ were referred. In sepsis and exchange transfusion $100 \%$ were passed. It was also found that $100 \%$ neonates were referred in case of mechanical ventilation and TORCH positive cases.

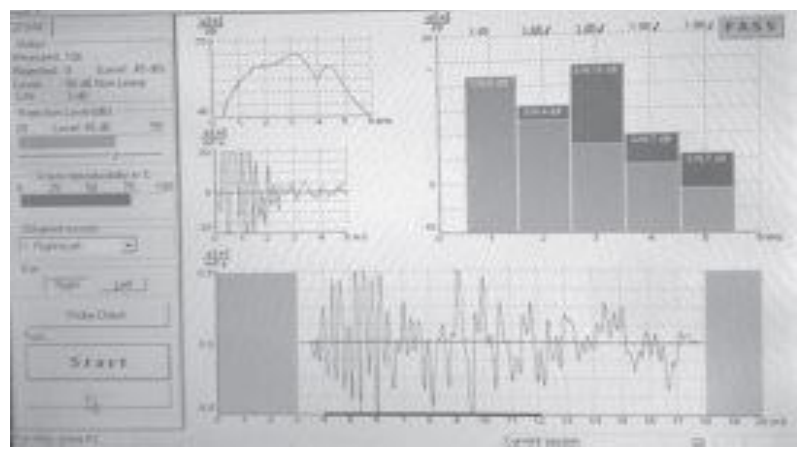

Fig.-5: A tracing of TEOAE showing pass result

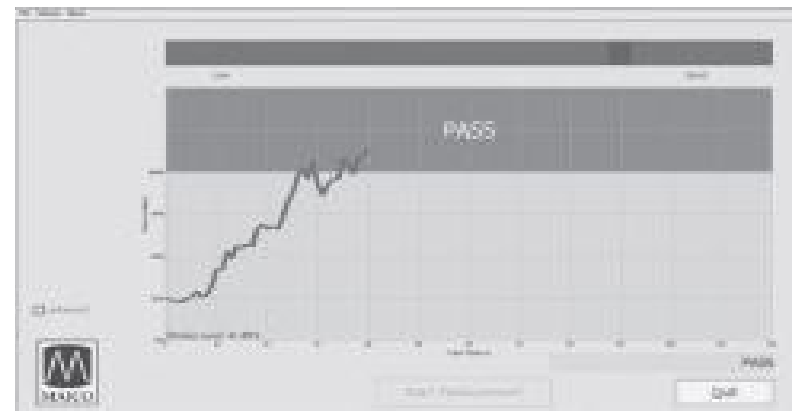

Fig.6: A tracing of $A A B R$ showing pass result

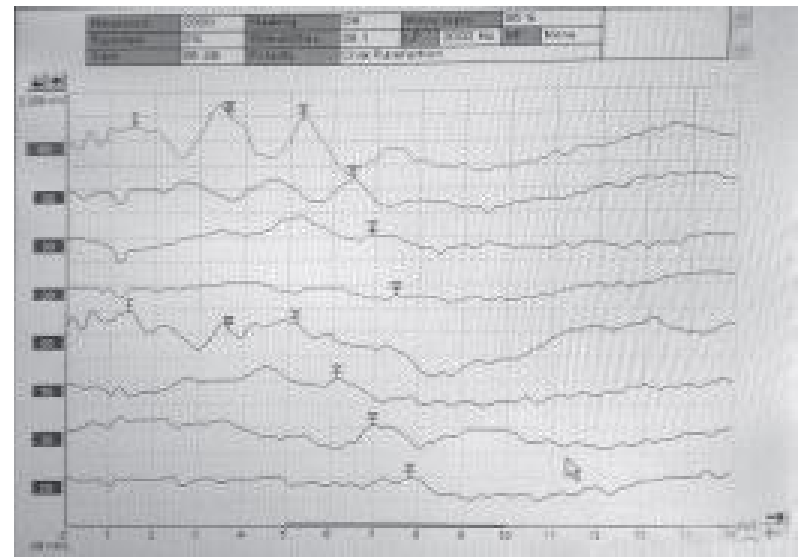

Fig.-7: A tracing of a diagnostic ABR showing different waves $(I, I I I, V)$ at different level of sound 


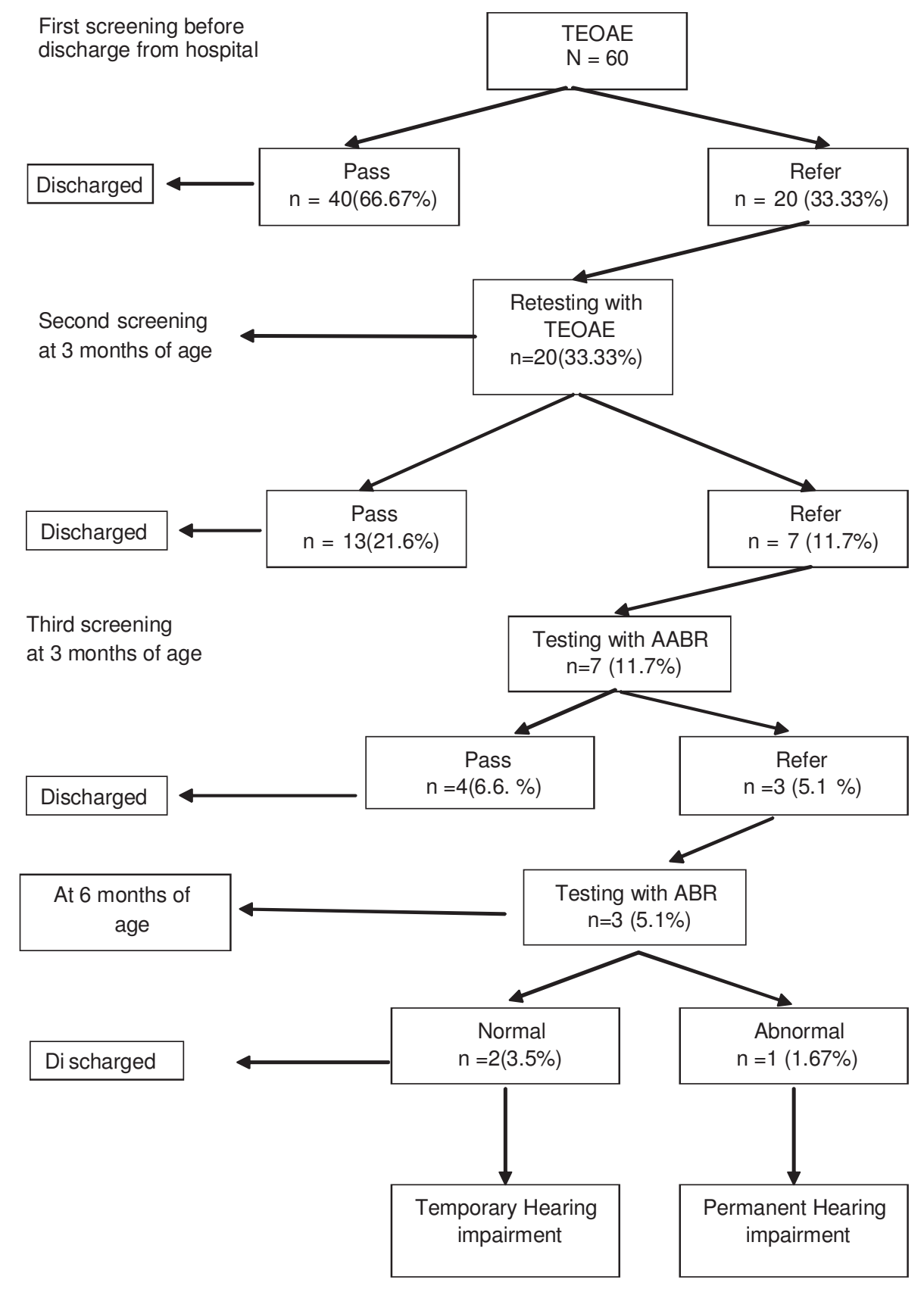

Fig.- 8: Flow chart of screening procedure and out come

\section{Discussion}

Hearing impairment is 20 times more prevalent in neonates than other disorders that are routinely screened by pediatrician. ${ }^{27}$ Early identification becomes necessary for initiation of rehabilitation at a time when brain is sensitive to the development of speech and language preferably by the age of 6 months. ${ }^{28}$

Besides, JCIH high risk factors, several other risk factors were observed from different studies that includes duration of intensive care, maternal diabetes, respiratory distress syndrome, meconium aspiration etc ${ }^{29}$. Among these factors common causes of hearing loss are prematurity, ${ }^{28}$ septicemia, ${ }^{10}$ and asphyxia ${ }^{3}$ that differed in proportion in different studies because of variation in sample size ${ }^{29}$ study design, study population and study area. ${ }^{28}$

In this study two-third of the patient was female and one third was male. This higher number 
of female newborn could not be explained. Twothird patient was delivered by Caesarian section and one third through home delivery. This might be due to admission of more complicated pregnant woman at hospital. Maternal risk factor was found in about one fourth cases. Among risk factors diabetes mellitus and hypertension were more prevalent and near to similar frequency.

In present study, birth weight $<1500$ gm was identified as the commonest risk factor 23 cases (38.33\%) followed by septicemia 13 cases (21.67\%), hyperbilirubinemia requiring exchange transfusion 10 cases (16.67\%), birth asphyxia 10 cases $(16.67 \%)$, and mechanical ventilation 3 cases $(5 \%)$ and TORCH infection one case $(1.67 \%)$. High risk factors of the present study correlate with many of the above study. ${ }^{10,28}$

In the study done by Nagapurnima et al. ${ }^{10}$ septicemia was found as the commonest risk factor $(56.63 \%)$ which was dissimilar to this study but other risk factors such as birth asphyxia $18.28 \%$, hyperbilirubinemia $13.62 \%$ were almost similar to this study.

In the study of Arora and Kochher, ${ }^{28}$ risk factors for hearing loss were low birth weight $41.42 \%$ and hyperbilirubinemia $25.71 \%$, septicemia $4.28 \%$, birth asphyxia $7.14 \%$. Both of the above two studies were carried out in developing country like us, where low birth weight and infection are common.

In another study, ${ }^{30}$ birth asphyxia was $17.9 \%$ which is similar to this study.

In this study initial hearing screening before discharge from hospital was done by TEOAE which is reproducible, diagnostically accurate, easy to perform and minimally invasive method of cochlear function. Currently it is the method of choice particularly for neonatal audiological screening among high-risk infants ${ }^{21}$ and general population. ${ }^{22}$ Referred (hearing deficit) cases were retested by TEOAE at 3 months of age to reduce the number of false positive cases $^{20}$ as well as to increase the specificity. ${ }^{17}$ Maturation of central nervous system may be responsible for this result ${ }^{20}$. Referred cases from TEOAE were retested by AABR to increase the sensitivity of the hearing status because this method can detect the auditory neuropathy also. ${ }^{24}$ Moreover, it was not influenced by ear canal defect like debris and middle ear effusion which were sensitive to TEOAE method. Thus AABR will reduce recall rate, overall expense and parental anxiety. ${ }^{7}$ In order to provide a precise and accurate diagnosis of hearing impairment, all infants who failed to pass the third stage were sent for diagnostic ABR evaluation and confirmation. ${ }^{31}$

Following the above hearing assessment protocol after $1^{\text {st }}$ screening $66.67 \%$ cases were passed (normal hearing) and $33.33 \%$ cases were referred. The result was almost similar to result of Olusanya study ${ }^{9}$ where $67.8 \%$ cases were passed and $32.2 \%$ cases were referred but dissimilar to the study of Bansal ${ }^{20}$ where $74.8 \%$ cases were passed and $25.2 \%$ cases were referred, and also finding of Kanne's study ${ }^{31}$ where pass finding in $91.1 \%$ cases and refer in $8.9 \%$ cases..

Second screening was done by TEOAE at 3 months of age where $65 \%$ of first screened referred cases were passed and 35\% cases were referred. This finding is not consistent with second screening finding of Capua study ${ }^{6}$ where $91.36 \%$ cases were passed and $8.64 \%$ cases were referred. Higher referral rate in this study might be due to inclusion of only selective high risk neonates but in Capua study both normal as well as high risk groups were screened.

Referred cases after second screening were re tested by AABR at 3 months of age where out of 7 patients $4(57.1 \%)$. were passed. Referred AABR cases were tested by diagnostic ABR at 6 months of age.

In this study out of 60 high risk neonates 1 was diagnosed as permanent hearing impairment that is 16.67 per 1000 screened neonates. This is similar to Olusanya study 9 where permanent hearing impairment was 16.7 per 1000 . In other studies the incidence was lower than this finding such as 2-4 per 1000 of Ehrenberg et al, ${ }^{15} 5.63$ per 1000 in Capua et al. ${ }^{6}, 10$ per 1000 in JS Oghalai ${ }^{27}$ et al, 10.75 per 1000 in Nagapurnima et al ${ }^{10}$ and 13.33 per 1000 in Connolly study. ${ }^{15}$ The 
incidence was higher than this present study was 38 per 1000 in the study of D'Souza et al ${ }^{3}$ and 34.48 per 1000 in study of Thomson et al. ${ }^{32}$

Among high risk factors perinatal asphyxia was statistically significant after $1^{\text {st }}$ screening which is similar to study of Kountakis et al. ${ }^{30}$ During follow-up retesting at 3 months of age it became insignificant because of cochlear immaturity and hypoxia producing transient middle ear effusion. ${ }^{6}$ Other risk factors were not statistically significant. This may be due to small sample size.

The study was conducted on small number of neonates and only selected high risk neonates were screened. No normal newborn was tested for comparison. So we recommend universal newborn hearing screening at a tertiary level hospital to find out the real incidence of hearing impaired neonates and infant.

\section{Conclusion:}

Permanent hearing impairment was 16.67 per 1000 high risk neonates in this study. Very low birth weight was found as the commonest risk factor and birth asphyxia was a significant risk factor for hearing impairment at initial screening but it was not consistent in subsequent follow up screening. As newborn hearing loss is an invisible or hidden disability, without any definite protocol early detection is quite difficult. In Bangladesh no protocol is yet established for neonatal hearing screening. This study focuses on the importance of initiating newborn hearing screening especially high risk neonates for early detection and intervention.

\section{Acknowledgement:}

We are grateful to the authority of audiology unit, Department of Otolaryngology, Head \& Neck Surgery, BSMMU, for their kind cooperation for screening the studied neonates free of cost.

\section{References}

1. Srour M, Mazer B, Shevell MI. Analysis of clinical features predicting etiologic yield in the assessment of global developmental delay. Pediatrics 2006; 118: 139-45.

2. Shevell MI, Majnemer A, Rosenbaum P, Abramowicz M. Etiologic yield of single domain developmental delay- a prospective study. J Pediatr 2000; 137: 633-7.

3. D'Souza SW, McCartney E, Nolan M, Taylor IG. Hearing, speech and language in survivors of severe perinatal asphyxia. Arch Dis Child 1981; 56: 245-52.

4. Misra PK, Katiyar CP, Kapoor RK, Shukla R, Malik GK, Thakur S. Brainstem auditory evoked response in neonates with birth asphyxia. Indian $\mathrm{J}$ Paediatr 1997; 34: 199-205.

5. Joint committee on Infant Hearing: 1994 Position Statement. Otolaryngol Head Neck Surg 1995; 113: 191-6.

6. Capua BD, Felice CD, Costantini D, Bagnoli F, Passali D. Newborn hearing screening by transient evoked otoacoustic emissions: analysis of response as a function of risk factors. Acta Otorhinolaryngol Ital 2003; 23: 16-20.

7. Finitzo T, Albright K, O'Neal J. The newborn with hearing loss: detection in the nursery. Pediatrics 1998; 102: 1452-60.

8. Lin HC, Shu MT, Chang KC, Bruna SM. A universal newborn hearing screening program in Taiwan. Int J Pediatr Otorhinolaryngol 2002; 63: 209-18.

9. Olusanya BO, Wirz SL, Luxon LM. Hospital- based universal newborn hearing screening for early detection of permanent congenital hearing loss in Lagos, Nigeria. Int. J Pediatr. Otorhinolaryngol 2008; 72:991-1001.

10. Nagapoornima P, Ramesh A, Srilakshmi, Rao S, Patricia PL, Gore M, et al. Universal hearing screening. Indian J Pediatr 2007; 74: 545-9.

11. Ng PK, Hui Y, Lam BCC, Goh WHS, Yeung CY. Feasibility of implementing a universal neonatal hearing program using distortion product otoacoustic emission detection at a university hospital in Hong Kong. Hong Kong Med J 2004; 10: 6-13.

12. Ali L, Siddiq S, Khan MA, Maqbool S. A hospitalbased universal newborn hearing screening program using transient evoked otoacoustic emission (TEOAE). Pakistan Pediatr J 2000; 24: 117-25.

13. Attias J, Al-Masri M, Abukadir L, Kohen G, Merlov $\mathrm{P}$, Pratt $\mathrm{H}$, et al. The prevalence of congenital and early-onset hearing loss in Jordanian and Israeli infants. Int Audiol 2006; 45: 528-36.

14. Khandekar R, Khabori M, Mohammed AJ, Gupta R. Neonatal screening for hearing impairmentthe Oman experience. Int $J$ Pediatr 2006, 70: 663-70.

15. Erenberg A, Lemons J, Sia C, Trunkel D, Ziring P. Newborn and infant hearing loss: detection 
and intervention. American Academy of Pediatrics Task Force on Newborn and Infant Hearing, 19981999. Pediatrics 1999; 103(2): 527-30.

16. Connolly JL, Carron JD, Roark SD. Universal newborn hearing screening: are we achieving the Joint Committee on Infant Hearing (JCIH) objectives? Laryngoscope 2005; 115(2): 232-6.

17. Prpic I, Mahulja-Stamenkovic V, Bilic I, Haller H. Hearing loss assessed by universal newborn hearing screening- The new approach. Int $\mathrm{J}$ Pediatr Otorhinolaryngol 2007; 71: 1757-61.

18. Olusanya BO, Luxon LM, Wirz SL. Childhood deafness poses problems in developing countries. BMJ 2005; 330: 480-1.

19. Kaushal M. Screening for hearing impairment in high-risk infant; multidisciplinary $\mathrm{CME}$ programme Paediatrics, AIIMS, 2003.

20. Bansal S, Gupta A, Nagarkar A. TEOAE in hearing screening programme- protocol for developing countries. Int. J Pediatr Otorhinolaryngol 2008; 72: 1059-63.

21. Pelosi G, Hatzopoulos S, Chierici R, Vigi V, Martini A. Evaluation of a linear TEOAE protocol in hearing screening of neonates : feasibility study. Acta Otorhinolaryngol Ital 1998; 18: 213.

22. Gillaw AW, Gosling D, Kelly C Walker P, Wooderson S. Predischarge screening in very low birth weight infants by click evoked Otoacoustic emissions. J Pediatr Child Health 1998; 34: 456-9.

23. Richardson MP, Williamson TJ, Reid A Tarlow MJ, Rudd PT. Otoacoustic emissions as a screening test for hearing impairment in children recovering from acute bacterial meningitis. Pediatrics 1998; 102(6): 1364-8.

24. Uus K, Bamford J. Hearing loss in preschool children: screening and surveillance. In: Glison M, Browning GG Burton MJ, et al, eds. ScottBrown's Otorhinolaryngology, Head and Neck Surgery. London: Hodder Arnold; 2008: p.824.

25. Early hearing detection and intervention-role of primary care physician. AAP CME teleconference, Part-I. Oct. 15, 2003.

26. Chanda S, Bais AS. Auditory Brainstem responses in high risk and newborns. Indian $\mathrm{J}$ Pediatr 1997; 64: 777-84.

27. Oghalai JS, Chen I, Brennan ML, Tonini R, Manolidis S. Neonatal hearing loss in the indigent. Laryngoscope 2002; 112: 281-6.

28. Arora S, Kochhar LK. Incidence evaluation of SNHL in high risk neonates. Indian $\mathrm{J}$ Otolaryngol Head Neck Surg 2003; 55(4): 246-49.

29. Kountakis SE, Skoulas I, Phillips D, Chang YJ. Risk factors for hearing loss in neonates:a prospective study. Am J Otolaryngol 2002; 23(3): 133-7.

30. Kanne TJ, Schaefer L, Perkins JA. Potential pitfalls in initiating a newborn hearing screening program. Arch Otolaryngol Head Neck Surg 1999; 125: 28-32.

31. Guastini L, Mora R, Dellepiane M, Santomauro V, Mora M, Rocca A, et al. Evaluation of an automated auditory brainstem response in multi-stage infant hearing screening. Eur Arch Otorhinolaryngol 2010; 267: 1199-1205.

32. Thomson AJ, Searle M, Russel G. Quality of survival after severe birth asphyxia. Arch Dis Child 1977; 52: 620-6. 